\title{
Assessment of Sexual Abuse Allegations in Child Custody Cases
}

\author{
James N. Bow, Francella A. Quinnell, Mark Zaroff, and Amy Assemany \\ Hawthorn Center
}

\begin{abstract}
Family courts frequently rely on the expertise of mental health professionals to assess allegations of sexual abuse within the context of child custody evaluations. Such evaluations are complex and require knowledge of techniques used in sexual abuse and sexual offender evaluations, as well as knowledge of child custody practices. Preliminary findings from a national survey of 84 psychologists indicated that respondents tend to adhere to the child custody guidelines of the American Psychological Association. However, few practitioners followed formal models, protocols, or guidelines when evaluating alleged victims or alleged perpetrators of sexual abuse in conjunction with child custody disputes. Implications for professional practice are discussed, along with a proposed comprehensive model for assessing sexual abuse allegations in child custody cases.
\end{abstract}

How do psychologists assess sexual abuse allegations within the context of child custody cases? This critical issue warrants close examination in light of the increased concern and attention such cases have captured in family court proceedings during the past 15 years. Sexual abuse allegations may surface prior to the divorce decree or after a custody/visitation agreement has been established. They can profoundly impact the proceedings and create an atmosphere of uncertainty and mistrust. Visitation or contact with the alleged perpetrator is often supervised or suspended, and the family court is often perplexed and overwhelmed by the complex decisions required in such cases. As a result, the court commonly seeks the expertise of mental health professionals to assess the veracity of such allegations.

The assessment of allegations of sexual abuse in custody cases is complex. First, a variety of family dynamics underlie such allegations. Motives of the parties involved may range from a need to protect the child because of safety concerns to vengeance, vindictiveness, and hostility over the marital break-up. Therefore, the evaluator needs to explore and understand the family system and evaluate the validity of the complaints. Second, in contrast to

JAMES N. Bow received his PhD from the University of Michigan. He is the director of psychology at the Hawthorn Center, Northville, MI, and a consultant and instructor for the Child Custody Program at Wayne State University, School of Medicine, Department of Psychiatry and Behavioral Neurosciences.

Francella A. QuinNell received her PhD from the University of Wisconsin at Milwaukee. She is presently an assistant professor of psychology at Northern Michigan University. She was previously a predoctoral intern at the Hawthorn Center.

MARK ZAROFF is a doctoral candidate at Central Michigan University. He was a predoctoral intern at the Hawthorn Center while the study was being conducted. He is currently in independent practice.

Amy Assemany is a doctoral candidate at the University of Albany, State University of New York. She was a predoctoral intern at the Hawthorn Center while the study was being conducted. She is presently in independent practice.

CORRESPONDENCE CONCERNING THIS ARTICLE should be addressed to James N. Bow, Hawthorn Center, 18471 Haggerty Road, Northville, Michigan 48167. E-mail: bow@michigan.gov extrafamilial cases, in custody cases the alleged perpetrator and other relevant parties are typically part of the evaluation process. As a result, better opportunities exist to gather a global and thorough view of the alleged event. Third, there is much overlap in the types of symptoms exhibited by children from high-conflict divorces and children who have been sexually abused, which makes it difficult to distinguish between the two groups (McGleughlin, Meyer, \& Baker, 1999). Lastly, the evaluator must have knowledge of three forensic areas: (a) practices and procedures in the child custody area, (b) sexual abuse evaluation techniques, and (c) assessment of alleged sexual offenders. The integration of these three areas provides an exceptionally challenging task for the evaluator.

Further complicating such evaluations, due to the high stakes and emotions involved, is an increased risk for board and ethical complaints and potential malpractice suits. Adhering to professional guidelines, such as the Specialty Guidelines for Forensic Psychologists (Committee on Ethical Guidelines for Forensic Psychologists, 1991) and the Guidelines for Child Custody Evaluations in Divorce Proceedings (American Psychological Association, 1994), is critical. Although the Committee on Professional Practice and Standards of APA (1995) has provided information about professional practice in the area of child abuse, APA has not formally endorsed comprehensive specialty guidelines for sexual abuse or offender evaluations.

Assessment of the alleged perpetrator is particularly difficult due to the high degree of denial among offenders, lack of an offender profile, and absence of a typical test profile for offenders (Becker \& Murphy, 1998; Underwager \& Wakefield, 1995). The use of techniques, such as penile plethysmograph and polygraph, is controversial in sex offender assessment (Haralambie, 1999). Also, many inventories that explore sexual feelings, thinking, and behaviors have obvious face validity, which makes it easy for the person being evaluated to deny or minimize sexual deviance. In an attempt to address some of these issues, the Association for the Treatment of Sexual Abusers (2001), Becker and Murphy (1998), Lanyon (2001), Quinsey and Lalumiere (2001), and Salter (1988) have outlined assessment guidelines or models. However, these procedures are intended for use with known sex offenders and focus on presentencing issues (e.g., risk appraisal) and treatment planning. 
The interview of the alleged victim is also complicated by numerous factors, such as memory skills, suggestibility, ability to distinguish reality from fantasy, and reliability of statements (Myers, 1992). The nature of the questioning by the evaluator plays a major role as well (Ceci \& Bruck, 1995; Kuehnle, 1996; Myers, 1992; Poole \& Lamb, 1998). Although APA has not endorsed or published guidelines for interviewing alleged victims, other professional groups have, including the American Academy of Child and Adolescent Psychiatry's (AACAP; 1997) Practice Parameters for the Forensic Evaluation of Children and Adolescents Who May Have Been Physically or Sexually Abused and the American Professional Society on the Abuse of Children's (1990) Guidelines for Psychosocial Evaluation of Suspected Sexual Abuse in Young Children. Also, Kuehnle (1996) and Poole and Lamb (1998) have developed comprehensive interview models. Yet guidelines are often not followed by professionals in the sexual abuse field (Poole \& Lamb, 1998; Underwager \& Wakefield, 1995). Another complication is the controversy surrounding the use of interview aids, such as anatomical dolls and projective drawings. Kuehnle (1996) and Poole and Lamb (1998) advocated caution in using these aids, noting that they are not diagnostic-specific for sexual abuse. The assessment process is further complicated by the lack of behavioral signs or symptoms that are diagnostic for sexual abuse (Haralambie, 1999; Kuehnle, 1996; Myers, 1992; Poole \& Lamb, 1998). Lastly, physical evidence is rare in sexual abuse allegations (Ellis, 2000; Haralambie, 1999).

Given the absence of comprehensive specialty guidelines for sexual offender and sexual abuse evaluations formally endorsed by APA, psychologists' practices in custody evaluations involving allegations of sexual abuse will probably be primarily directed by guidelines in the child custody field (APA, 1994). These guidelines outline the purpose of the evaluation and procedures to follow, thereby providing parameters for professional practice. Psychologists performing typical child custody evaluations have been found to benefit from such direction, with practices and procedures adhering to APA guidelines (Bow \& Quinnell, 2001).

The presence of sexual abuse allegations complicates child custody evaluations. Given the absence of relevant practice guidelines and the controversy surrounding assessment in this area, it is not surprising that evaluators have been strongly criticized (Myers, 1997; Zorza, 1999). In fact, Myers (1997) bluntly stated that no more than $10 \%$ of child custody evaluators are actually knowledgeable about child sexual abuse. The present study aims to ascertain the validity of this criticism by identifying the practices and procedures used by psychologists in such evaluations and determining the value placed on certain techniques and data sources in the assessment process.

\section{Preliminary Findings: A Survey of Sexual Abuse Allegations in Child Custody Evaluations}

\section{Participants}

Potential participants for this exploratory study were derived from numerous sources, including an Internet search of clinical and forensic psychologists listing child custody as a specialty, referral lists in the public domain of forensic psychologists who perform child custody evaluations, and child custody evaluators known to the first author through conferences and publications. A random sample of forensic and clinical psychologists was not used because of the great difficulty in locating child custody evaluators, particularly those who do custody work involving sexual abuse allegations.

A survey instrument was developed to analyze all aspects of sexual abuse allegations in child custody cases. A cover letter, informed consent sheet, blank survey, stamped return envelope, and stamped postcard requesting results were sent to all potential participants. Those currently conducting sexual abuse evaluations in custody cases were asked to anonymously complete and return the survey. Those who no longer performed child custody evaluations or declined child custody evaluations involving sexual abuse allegations were requested to indicate such on the form and return it. Those interested in the results of the study were asked to return the enclosed postcard separately. Potential participants were informed that all data would be coded and analyzed on a group basis to protect confidentiality. Approximately 3 weeks later, a reminder postcard was sent to potential participants.

A total of 368 surveys were mailed to potential participants, and 147 of them were returned $(40 \%)$. Of these, 84 were usable surveys (i.e., completed surveys from psychologists currently performing child custody evaluations involving sexual abuse allegations). In terms of the remaining returned surveys, 24 of the respondents indicated that they no longer performed child custody evaluations, 15 indicated that they decline child custody evaluations involving sexual abuse allegations, 17 were undeliverable, 4 declined to participate, and 3 surveys were substantially incomplete.

The gender of respondents was predominately male (62\%). The average age of respondents was 53 years $(S D=6.71)$, with a range of 36 to 73 years. Ninety-eight percent were doctoral-level psychologists, with the vast majority trained in clinical psychology (71\%), followed by counseling psychology (13\%) and school psychology (8\%). Sixteen percent of the sample were diplomates of the American Board of Forensic Psychology. The overwhelming majority of respondents worked in independent practice $(89 \%)$ in an urban area (91\%). Respondents represented 28 states, with the following geographic distribution: $21 \%$ from the West, $25 \%$ from the South, $31 \%$ from the Midwest, and $17 \%$ from the East, with $6 \%$ unspecified.

Professional experience averaged 22.35 years in the clinical field $(S D=6.66), 16.51$ years in the sexual abuse area $(S D=6.21)$, and 14.95 years in the child custody field $(S D=6.13)$. The average number of child custody evaluations completed by respondents during their career was 331, with a median and mode of 200. Respondents had performed an average of 52 child custody evaluations involving sexual abuse allegations, with a median of 25 and completion of either 10 or 50 evaluations most frequently reported. Twenty percent of respondents indicated they did not perform sexual abuse evaluations outside of child custody work; 39\% reported similar limitations on the performance of sex offender evaluations.

Respondents were asked to rate their forensic knowledge base on a Likert scale ranging from 1 (none) to 5 (extensive). The average rating was 4.40 , with $93 \%$ of respondents providing a rating of 4 or 5 . Therefore, this sample viewed itself as very well versed in the forensic area.

Overall, this sample of child custody evaluators was a highly educated and experienced group of forensic psychologists working 
in independent practice in an urban area and may not be representative of typical child custody evaluators. Furthermore, the relatively small sample size may limit generalization of the findings. In light of these limitations, the findings should be considered preliminary.

\section{Nature of Referrals}

The vast majority of custody referrals (84\%) were court ordered. In $60 \%$ of the cases, allegations of sexual abuse preceded the initial custody/visitation determination. Modification of the original custody/visitation agreement was requested in $40 \%$ of the cases. The biological father was identified as the most common alleged perpetrator in these types of evaluations (55\%), followed by the stepfather $(25 \%)$, biological mother $(11 \%)$, and the "other" category-including relatives and significant others (11\%), siblings $(9 \%)$, and stepmother $(4 \%)$. The majority of alleged victims $(76 \%)$ were under the age of 10 , with $52 \%$ under the age of 7 . Less than $10 \%$ of the alleged victims were over the age of 12 . The lower figure with older children is probably due to their ability to better defend themselves, their greater resistance to parental alienation and manipulation, and their possession of sufficient verbal skills to report abuse. These figures regarding the ages of victims are similar to Thoennes and Tjaden's (1990) findings.

\section{Evaluation Procedures Used}

The specific procedures used by the respondents during the evaluation process are displayed in Table 1. All respondents interviewed the accusing parent and alleged perpetrator, and almost all conducted psychological testing. Alleged victims were almost always interviewed, but psychological testing was performed less frequently. All but one respondent reported reviewing records. Record review was the most labor-intensive activity $(M=5.36$ $\mathrm{hr}$ ), with considerably more time spent than the average $2.97 \mathrm{hr}$ associated with the typical child custody evaluation (Bow \& Quin- nell, 2001). Similarly, more time was required for interviews and testing than was found in the earlier study (Bow \& Quinnell, 2001) for typical child custody evaluations. The increased time needed to complete these evaluations is probably due to the complexity of the assessment, past legal and agency involvement, and the seriousness of the allegation and possible ramifications.

Only $25 \%$ of respondents reported interviewing the alleged perpetrator and alleged victim together; however, a greater proportion of respondents $(58.5 \%)$ conducted parent-child observation sessions with the alleged perpetrator and victim. The utmost concern about these types of procedures is the possible psychological risk to the child. Also, it is important to note that there is no empirical support that an observation of the child and alleged perpetrator will help accurately differentiate sexually abused children from those who have not been sexually abused (McGleughlin et al., 1999). Almost all respondents typically used a variety of collateral contacts, as stressed in the APA custody guidelines and sexual abuse/offender comprehensive models.

Table 2 shows the percentage of respondents using particular tests with the accusing parent and the alleged perpetrator when psychological testing was included in the evaluation process. The types of tests administered were similar for both parties, with the administration of some specialized sex offender instruments with the alleged perpetrator. Personality tests were most popular, with the Multiphasic Personality Inventory-2 (MMPI-2), Millon Clinical Multiaxial Inventory-III (MCMI-III), and Rorschach given most often and at a frequency comparable to that found in typical child custody evaluations (Quinnell \& Bow, 2001). However, IQ testing and parenting scales were used less frequently than in typical child custody evaluations, which may be explained by the difference in the focus of the evaluation (i.e., sexual abuse allegations vs. cognitive functioning or care-giving abilities).

Parent rating scales (e.g., Child Behavior Checklist, Connors Parent Rating Scale) were used by only four respondents, which is surprising considering that a child's social-emotional functioning

Table 1

Procedures Used in Child Custody Cases Involving Sexual Abuse Allegations

\begin{tabular}{lccc}
\hline \multicolumn{1}{c}{ Procedure } & \% using procedure & Average no. sessions & Average hr \\
\hline Interview of accusing parent & 100 & 2.89 & 4.30 \\
Interview of alleged perpetrator & 100 & 2.96 & 4.48 \\
Interview of alleged victim & 98.8 & 3.03 & 3.64 \\
Review of records & 98.8 & & 4.36 \\
Testing of alleged perpetrator & 97.6 & & 3.96 \\
Testing of accusing parent & 95.1 & 1.88 & 2.22 \\
Interview with siblings & 92.6 & & 2.94 \\
Testing of alleged victim & 66.3 & & \\
Interview of others & 65.8 & & \\
Collateral contacts & & & \\
School & 97.6 & & \\
Protective services & 96.4 & & \\
Alleged victim's therapist & 96.4 & & \\
Alleged perpetrator's therapist & 96.4 & & \\
Accusing parent's therapist & 96.4 & & \\
Physician & 92.6 & & \\
Police & 90.1 & & \\
Relatives & 76.8 & & \\
Friends & 66.3 & & \\
\hline
\end{tabular}


Table 2

Percentage of Respondents Who Use Particular Psychological Tests in Child Custody Cases With Sexual Abuse Allegations

\begin{tabular}{lcc}
\hline \multicolumn{1}{c}{ Specific test } & Accusing parent (\%) & Alleged perpetrator (\%) \\
\hline Minnesota Multiphasic Personality Inventory-2 & 96 & 94 \\
Millon Clinical Multiaxial Inventory-III & 55 & 54 \\
Rorschach Inkblot Test & 41 & 40 \\
Parenting Stress Index & 22 & 21 \\
Parent Child Relationship Inventory & 15 & 15 \\
Thematic Apperception Test & 15 & 15 \\
Wechsler Adult Intelligence Scale (3rd ed.) & 15 & 14 \\
Sentence Completion & 13 & 13 \\
IQ screening instruments & 6 & 5 \\
Child Sexual Behavior Inventory & 5 & 3 \\
Personality Assessment Inventory & 5 & 5 \\
NEO Personality Inventory & 4 & 6 \\
Child Abuse Potential Inventory & 4 & 4 \\
Abel Screening Assessment & 1 & 8 \\
Multiphasic Sex Inventory (I or II) & 0 & 10 \\
\hline
\end{tabular}

is usually impacted by sexual abuse, and these scales provide a good assessment of this area. Furthermore, only four respondents reported using the Child Sexual Behavior Inventory (CSBI), an inventory specifically developed to assess signs and symptoms of sexual abuse.

Twenty-one percent of respondents reported administering sex offender inventories, scales, or psychosexual history forms to the alleged perpetrator. The most commonly used instrument was the Multiphasic Sex Inventory (MSI). Although the original version of the MSI is designated to be used only when the alleged perpetrator has acknowledged the sexual offense (Nichols \& Molinder, 1984; Underwager \& Wakefield, 1995), the second version (MSI-II; Nichols \& Molinder, 1996) is appropriate for alleged sex offenders. Of those using the MSI, only $25 \%$ indicated that they had used the second version. Therefore, the vast majority may be inappropriately using the original version. The Abel Assessment was used by $8 \%$ of the respondents. No more than a couple of respondents used any of the other sex offender inventories or scales.

Sixty-six percent of respondents indicated that they tested the alleged victim. Of those respondents identifying the specific tests, the most commonly identified instruments were the Rorschach Inkblot Test (33\%), Wechsler Intelligence Scale for Children (3rd ed.) or an IQ screening measure (31\%), Thematic Apperception Test or Children's Apperception Test (27\%), Sentence Completion (25\%), House-Tree-Person or Human Figure Drawing (21\%), and Family Drawing (19\%). The use of projective instruments raises concerns; Lilienfield, Wood, and Garb (2000) cautioned against using projective techniques in forensic evaluations. Furthermore, such instruments are not diagnostic for sexual abuse (Dammeyer, 1998; Kuehnle, 1998).

\section{Specialized Interviews}

Alleged victim. Only $36 \%$ of respondents reported using a sexual abuse protocol, model, or guidelines in child custody evaluations involving sexual abuse allegations. This figure is only slightly lower than Conte, Sorenson, Forgarty, and Peela Rosa's (1991) survey of professionals that found $40 \%$ used a written protocol in the process of assessing sexual abuse allegations. Of those using such a protocol, model, or guideline in the present study, $37 \%$ of respondents revealed that they developed their own, whereas 23\% applied Kuehnle's (1996) model, 23\% applied Poole and Lamb's (1998) model, and 10\% drew upon Gardner's (1992) work.

During the interview of the alleged victim, the overwhelming majority of respondents reported assessing areas that are part of most sexual abuse interview protocols (see Table 3 ). The lone exception was "good and bad touches" (Walker \& Hunt, 1998). Nonetheless, without the ability to refer to a specific sexual abuse protocol, it is difficult to know whether the interview information was gathered in an empirically supported manner. Overall, the underutilization of sexual abuse protocols, models, or guidelines raises serious concerns, especially with regard to the defensibility of the interview procedures in court.

The percentage of respondents using various interview aids with alleged victims and the average diagnostic value placed on such aids are displayed in Table 4. All have dubious diagnostic value, and none should be used to differentiate sexually abused children from those who have not been sexually abused, although some of the techniques (e.g., play and drawing) may be useful for rapport building. The least used and valued aid - anatomical dolls- has been the focus of major debate (Kuehnle, 1996; Poole \& Lamb,

Table 3

Areas Assessed During Interview With Alleged Victim

\begin{tabular}{lc}
\hline \multicolumn{1}{c}{ Specific area } & $\begin{array}{c}\text { \% of respondents } \\
\text { assessing area }\end{array}$ \\
\hline Social-emotional functioning & 98.8 \\
General cognitive development & 97.6 \\
Memory for past events & 93.9 \\
Understanding of truth and lies & 91.5 \\
Language development & 89.0 \\
Secrets & 87.8 \\
Sexual knowledge & 86.6 \\
Body parts terminology & 85.4 \\
Good and bad touches & 80.5 \\
Suggestibility and "correct me" & 76.8 \\
\hline
\end{tabular}


Table 4

Usage Rates and Diagnostic Value of Interview Aids With Alleged Victims of Sexual Abuse in Custody Evaluations

\begin{tabular}{|c|c|c|c|c|c|c|c|}
\hline \multirow[b]{2}{*}{ Type of aid } & \multirow{2}{*}{$\begin{array}{c}\% \text { of respondents } \\
\text { using aid }\end{array}$} & \multicolumn{5}{|c|}{$\%$ of respondents ascribing specific values } & \multirow{2}{*}{$\begin{array}{l}\text { Average value } \\
\text { rating }\end{array}$} \\
\hline & & 1 & 2 & 3 & 4 & 5 & \\
\hline Projective drawings & 67.5 & 25.8 & 7.6 & 25.8 & 22.7 & 18.2 & 3.0 \\
\hline Timeline & 53.8 & 26.6 & 9.4 & 21.9 & 25.0 & 17.2 & 3.0 \\
\hline Play therapy & 47.5 & 34.4 & 18.0 & 16.4 & 19.7 & 11.5 & 2.6 \\
\hline Anatomical drawings & 43.9 & 27.9 & 18.0 & 26.2 & 18.0 & 9.8 & 2.6 \\
\hline Doll house & 35.4 & 38.1 & 27.0 & 19.0 & 9.5 & 6.3 & 2.2 \\
\hline Puppet play & 33.8 & 36.7 & 23.3 & 28.3 & 6.7 & 5.0 & 2.2 \\
\hline Anatomical dolls & 21.0 & 36.1 & 34.4 & 16.4 & 8.2 & 4.9 & 2.1 \\
\hline
\end{tabular}

Note. Values ranged from 1 (no value) to 5 (very valuable).

1998), which may be the reason for its limited usage and perceived low value.

Respondents were also asked if they typically audiotaped or videotaped the interview with alleged victims. Only $30 \%$ answered in the affirmative. There is much debate over the pros and cons of electronic recording (Myers, 1992; Poole \& Lamb, 1998). However, research by Lamb, Orbach, Sternberg, Hershkowitz, and Horowitz (2000) showed the superiority of electronic recording over "verbatim" notes, thereby, providing strong support for its use.

Alleged perpetrator. Only $30 \%$ of respondents reported using a protocol, model, or guideline for the assessment of the alleged sexual offender in child custody cases. Of those using a protocol, model, or guidelines, $35 \%$ indicated they developed their own. Nine percent of the respondents indicated that they used each of the following: Hare's Psychopathy Checklist-Revised (PCL-R), MSI (I or II), or Abel Assessment. It is important to note that the PCL-R is based on Hare's (1998) definition of psychopathy and is normed on forensic populations (e.g., individuals in institutional or community correctional facilities, forensic psychiatric hospitals, or detention facilities), and it does not specifically assess sexual offending per se. Therefore, the use of the PCL-R with "alleged perpetrators," outside of the normative group, is inappropriate. Seventeen percent of respondents indicated that they refer this portion of the evaluation to an outside expert and then incorporate those findings into their report.

The vast majority of respondents assessed important content areas with the alleged sexual perpetrator (see Table 5). However, areas most frequently assessed were those most easily evaluated by traditional interviews and tests. Areas requiring specialized questioning and inventories, such as sexual fantasies, sexual arousal patterns, and sexual boundaries, were assessed less frequently. Each area was rated at least moderately high in terms of usefulness in the evaluation process. Those rated highest in value (i.e., history of sexual offending, personality functioning, and antisocial traits) are commonly part of sex offender risk-assessment inventories.

\section{Value of Evidence}

Respondents were asked to rank order from 1 to $10(1=$ most important, 10 = least important) the value of different procedures or sources of information in the evaluation process (see Table 6). Interviews and collateral sources (records and medical evidence) were seen as most valuable, whereas less value was placed on psychological testing and observations. The usefulness of specific data sources in the evaluation process was rated on a 5-point Likert scale ranging from 1 (no value) to 5 (very valuable). As reflected in Table 7, all sources received mean ratings of 3 or higher. The most valued information was medical evidence, with close to $50 \%$ of respondents rating this as very valuable. This is probably due to the fact that physical or medical evidence is rare (Ellis, 2000; Haralambie, 1999; Myers, 1992), so its presence is highly significant and valued. Reports from Protective Services and the police were the next most valued, probably because they allow the evaluator to confront the alleged sexual perpetrator over inconsistencies in his or her story. Penile plethysmograph findings were

Table 5

Specific Factors Assessed in Alleged Sexual Perpetrators in Child Custody Cases

\begin{tabular}{lcc}
\hline \multicolumn{1}{c}{ Specific factor } & $\begin{array}{c}\text { \% of respondents } \\
\text { assessing factor }\end{array}$ & $\begin{array}{c}\text { Average value as } \\
\text { diagnostic indicator }\end{array}$ \\
\hline History of sexual abuse & 97.6 & 3.97 \\
Personality functioning & 96.3 & 4.15 \\
Antisocial traits & 96.3 & 4.14 \\
Social skills & 96.3 & 3.93 \\
History of sexual offending & 96.3 & 4.56 \\
Thinking errors & 86.3 & 3.74 \\
Sexual fantasies & 75.6 & 3.64 \\
Sexual arousal patterns & 72.0 & 3.65 \\
Sexual boundaries & 71.4 & 3.78 \\
\hline
\end{tabular}

Note. Diagnostic values range from 1 (no value) to 5 (very valuable). 
Table 6

Ranking of Procedures in Custody Cases With Sexual Abuse Allegations

\begin{tabular}{clcc}
\hline Ranking & \multicolumn{1}{c}{ Procedure } & Average rank & $S D$ \\
\hline 1 & Interview with alleged victim & 2.54 & 1.73 \\
2 & Interview with alleged perpetrator & 3.96 & 2.01 \\
3 & Records & 3.97 & 2.94 \\
4 & Medical evidence & 4.20 & 2.97 \\
5 & Interview with accusing parent & 4.46 & 2.48 \\
6 & Psychological testing of perpetrator & 5.92 & 2.21 \\
7 & Psychological testing of victim & 6.75 & 2.81 \\
8 & Psychological testing of accusing parent & 6.91 & 2.04 \\
9 & Observation of alleged victim \& perpetrator & 7.24 & 2.24 \\
10 & Observation of alleged victim \& accusing parent & 7.42 & 2.31 \\
\hline
\end{tabular}

Note. Procedures were ranked on a 10 -point scale $(1=$ most important, $10=$ least important $)$. Procedures were ranked on the basis of the average rating received.

rated as moderately valuable, although the tool cannot identify if someone has committed a specific sexual offense (Becker \& Quinsey, 1993). Polygraph findings were the least valued, which likely reflects the controversy surrounding its use and consistent rulings that the results are inadmissible in court (Haralambie, 1999).

Respondents were asked to rate the value of different sexual abuse concepts in the assessment process on a Likert scale, ranging from 1 (useless) to 5 (very useful), with $U F$ indicating a lack of familiarity with the concept (see Table 8). Only the presence of sexualized behavior and parent alienation syndrome received mean ratings above 3 , with almost $50 \%$ of respondents giving these concepts a rating of 4 or 5 . Sexualized behavior is more common in sexually abused children, although the presence of such behavior is not diagnostic (Kendall-Tackett, Williams, \& Finkelhor, 1993). Parent alienation syndrome, a term coined by Gardner (1987), is controversial mostly because of its reference to a syndrome (Stahl, 1999). Many others have expanded the concept beyond the sexual abuse area to include any alienation or alignment of children in divorce situations, which may be the reason it was rated relatively high in this study. The other three concepts, the Sexual Abuse Legitimacy Scale by Gardner (1992), the child sexual abuse accommodation syndrome (Summit, 1983), and the child sexual abuse syndrome, ${ }^{1}$ all received mean ratings below 2 . This is a positive finding in that all three concepts lack empirical support for their ability to accurately identify sexually abused children (Haralambie, 1999; Myers, 1992). However, a relatively high percentage of respondents were unfamiliar with the concepts, which is troublesome considering they are often discussed in the sexual abuse literature.

\section{Reporting the Findings}

Respondents reported that it took an average of 9 weeks to complete a child custody evaluation involving sexual abuse allegations, which is commensurate with a typical child custody evaluation (Bow \& Quinnell, 2001). On average, these evaluations took $21.79 \mathrm{hr}$, with an additional $10.25 \mathrm{hr}$ for the report. The total time $(M=32.04 \mathrm{hr}$ ) was $7.5 \mathrm{hr}$ longer than the typical custody evaluation involving two parents and one child (Bow \& Quinnell, 2001). This is expected considering the complexity of the evalu- ation and the length of the report ( $M=25.42$ pages), along with the additional time needed to review documents and to interview and test adults.

On average, respondents reported that they supported allegations of sexual abuse in about $30 \%$ of child custody cases. This figure is consistent with Wakefield and Underwager's (1991) findings but lower than the figures obtained in studies by McGraw and Smith (1992; 44.6\%), Benedek and Schetky (1985; 45\%), and Thoennes and Tjaden (1990; 50\%). These figures may vary depending on the sample (e.g., court clinic vs. outside expert) and criteria used to support abuse.

\section{Discussion}

\section{Implications of Findings}

Assessment of sexual abuse allegations in child custody cases is a complex and difficult task. Although professional guidelines are provided for performing child custody evaluations (APA, 1994), APA provides no formal, comprehensive guidance in the evaluation of alleged sexual abuse or sexual offending in general or within the context of child custody disputes in particular. This state of affairs is reflected in the preliminary findings of the present survey of psychologists conducting child custody evaluations involving sexual abuse allegations. The evaluations adhered to the APA child custody guidelines. In most cases, they were court ordered, comprehensive, and included multiple data sources (e.g., interviews, psychological testing, observations, collateral contacts, and review of records) and closely reflected practices and procedures employed in typical child custody evaluations. Apparent differences, such as a decline in parent-child observations when one of the parent figures is the alleged perpetrator and less frequent use of parenting inventories, appear due to the nature and focus of the evaluation (i.e., sexual abuse allegation).

In terms of assessing the allegations of sexual abuse and sexual offending, respondents seemed to struggle. Although they reported assessing many of the critical areas found in sexual abuse and sexual offending protocols, only about one third actually used a

\footnotetext{
${ }^{1}$ It is unclear who coined the term child sexual abuse syndrome, but the term is often referred to in legal cases (Palmer-Percy, 1992).
} 
Table 7

Value of Specific Data Sources in the Assessment of Sexual Abuse Allegations in Child Custody Cases

\begin{tabular}{lcr}
\hline \multicolumn{1}{c}{ Specific data source } & Average value & $S D$ \\
\hline Medical evidence & 4.15 & 0.99 \\
Protective services report & 3.96 & 0.81 \\
Police report & 3.64 & 0.94 \\
Penile plethysmograph findings & 3.28 & 1.24 \\
Therapist's letter & 3.25 & 1.14 \\
Polygraph results & 3.16 & 1.11 \\
\hline
\end{tabular}

Note. Value was rated on a Likert scale from 1 (no value) to 5 (very valuable).

formal protocol, model, or guidelines. Most respondents indicated that they developed their own protocols. Furthermore, in the assessment of the alleged sexual perpetrator, specialized questionnaires or inventories were infrequently used, and when used, were sometimes inappropriate. The infrequent use of formal, standardized protocols/guidelines with alleged victims and perpetrators along with the infrequent or inappropriate use of some instruments with the alleged perpetrator raises serious questions, especially regarding the defensibility of findings and practice in a court of law. In addition, respondents ranked the interviews with the alleged victim and alleged perpetrator as the most important data sources, which further highlight the need for legally defensible interviews. The apparent need for comprehensive practice guidelines suggests that APA should take a leadership role in formally endorsing guidelines for assessing allegations of sexual abuse and sexual offending, especially in conjunction with child custody disputes. In the interim, we outline a comprehensive model for assessing allegations of sexual abuse in custody disputes that was developed through a thorough review of the child custody, sexual abuse, and sexual offender literature, consultation with other experts, and the professional experience of the first author.

\section{Proposed Comprehensive Model}

1. Role of the evaluator( $(s)$. The forensic evaluator should have no prior involvement with the case (i.e., not a current or past therapist) and should be appointed by the court as an independent evaluator to promote a neutral, objective role. Written informed consent must be obtained from all parties. The focus of the evaluation is on the best interests of the child (APA, 1994). The evaluator(s) must consider multiple hypotheses and be aware of personal biases that may affect the evaluation (APA, 1994). The sole evaluator must also have expertise in all phases of the evaluation (i.e., custody, sexual abuse, and sexual offender). If a sole evaluator lacks such expertise, a referral to an outside expert in that particular area should be sought or a team approach utilized. The pros and cons of the sole evaluator versus the team approach are provided in Table 9. In many cases, a team approach might be preferred. Nonetheless, the approach taken must be consistent with the scope of the court order for risk-management purposes.

2. Review of the records. It is critical for the evaluator(s) to review all records pertaining to the case, including police documents, Protective Services reports, medical records, and therapy records. It is important that records be reviewed prior to or shortly after the evaluation process begins. Information gathered will assist in formulating questions and addressing inconsistencies. This is particularly important in regard to the interview with the alleged perpetrator. Also, it is important to be aware of the number of times the alleged victim was previously interviewed, by whom the interview was conducted, the context and protocol used, and the time interval(s) between interviews. Repeated suggestive interviews may decrease the accuracy of a child's report (Ceci \& Bruck, 1995; Poole \& Lamb, 1998).

3. Assessment of nature, sequence, and circumstances of the allegation $(s)$. It is paramount that the evaluator(s) understand the

Table 8

Value of Various Concepts in the Assessment of Sexual Abuse

\begin{tabular}{|c|c|c|c|c|c|c|c|}
\hline \multirow[b]{2}{*}{ Concept } & \multicolumn{6}{|c|}{$\%$ of respondents } & \multirow[b]{2}{*}{ Average rating } \\
\hline & UF & 1 & 2 & 3 & 4 & 5 & \\
\hline $\begin{array}{l}\text { Presence of sexualized } \\
\text { behavior }\end{array}$ & 4.9 & 2.4 & 7.3 & 26.8 & 36.6 & 22.0 & 3.54 \\
\hline Parent alienation syndrome & 1.2 & 11.1 & 11.1 & 18.5 & 34.6 & 23.5 & 3.44 \\
\hline $\begin{array}{l}\text { Gardner's Sexual Abuse } \\
\text { Legitimacy Scale }\end{array}$ & 20.7 & 34.1 & 14.6 & 14.6 & 11.0 & 4.9 & 1.76 \\
\hline $\begin{array}{l}\text { Child sexual abuse } \\
\text { syndrome } \\
\text { Child sexual abuse } \\
\text { accommodation } \\
\text { syndrome }\end{array}$ & 31.3 & 19.3 & 16.9 & 13.3 & 16.9 & 2.4 & 1.72 \\
\hline
\end{tabular}

Note. Value was rated on a Likert scale from 1 (useless) to 5 (very useful). UF $=$ unfamiliar with concept. 
Table 9

Pros and Cons of Sole Versus Team Evaluation Approaches

\begin{tabular}{|c|c|}
\hline Sole approach & Team approach \\
\hline \multicolumn{2}{|l|}{ Pros } \\
\hline 1. Easier to coordinate process. & $\begin{array}{l}\text { 1. Can best match expertise of each evaluator } \\
\text { to evaluation task. }\end{array}$ \\
\hline 2. Evaluator has global view of all aspects of evaluation. & 2. Reduces possible personal biases. \\
\hline 3. Lack of repetitive questioning among parties. & 3. Provides a check and balance. \\
\hline $\begin{array}{l}\text { 4. Easier to follow-up on questions because of first-hand } \\
\text { knowledge of all parties' data. }\end{array}$ & 4. Offers different perspectives. \\
\hline \multicolumn{2}{|l|}{ Cons } \\
\hline 1. Potential bias. & $\begin{array}{l}\text { 1. Time-consuming for a number of } \\
\text { evaluators. Also, requires numerous } \\
\text { meetings among evaluators to discuss and } \\
\text { evaluate data. }\end{array}$ \\
\hline 2. Lack of check and balance. & $\begin{array}{l}\text { 2. Difficult to coordinate schedules of parties } \\
\text { and evaluators. }\end{array}$ \\
\hline 3. Need expertise in all areas assessed. & $\begin{array}{l}\text { 3. Potential for evaluation process to be } \\
\text { disjointed. }\end{array}$ \\
\hline & $\begin{array}{l}\text { 4. Numerous people may have to testify, } \\
\text { which is time consuming. Also, greater } \\
\text { potential for inconsistencies in testimony } \\
\text { of evaluators. }\end{array}$ \\
\hline
\end{tabular}

time sequence, motives, and dynamics surrounding the allegation of sexual abuse (Ehrenberg \& Elterman, 1995). Did the allegation occur prior to the separation or after the divorce? Who made the allegation? Where did the alleged behavior occur? What possible motives are involved? Have other allegations been made? It also is important to assess family stressors and triggers beyond the separation/divorce, such as remarriage or a change in child support or visitation. Furthermore, evaluation of the nature of the allegation and the plausibility of the alleged occurrence is critical.

4. Procedures. Multiple data sources must be used (APA, 1994; Committee on Ethical Guidelines for Forensic Psychologists, 1991), with all parties participating in the evaluation. Interviews, psychological testing, collateral contacts, and documentation review should always be included and, in most cases, parent-child observations should be included as well. It is strongly recommended that each party be interviewed a number of times. A thorough psychosocial history needs to be gathered from all parties, along with their respective views of the allegation. In addition, detailed information should be gathered about the alleged victim's pre- and postallegation psychological functioning, the family's sexual attitudes and beliefs, the child and family's terminology for sexual parts, the child's exposure to sex education material, and past sexual overstimulation or abuse. All data gathered should be carefully recorded and preserved (APA, 1994; Committee on Ethical Guidelines for Forensic Psychologists, 1991).

5. Interviews with the alleged victim. Kuehnle (1996) and Poole and Lamb (1998) have developed forensic interview protocols for assessing sexual abuse, which follow a comprehensive model. Such protocols should enhance the defensibility of the assessment process in court by reducing leading questions and lessening concerns about suggestibility. Evaluators should not underestimate the need for training and experience to competently administer these protocols. It is also important to note that these protocols eliminate the inappropriate use of projective tests, drawings, artwork, and play therapy for diagnostic purposes. Due to the controversy surrounding anatomical dolls, it is recommended this technique not be used. The alleged victim should be interviewed alone, and all sessions should be audiotaped or videotaped, with the latter preferred. In evaluating the child interview, the following should be considered: (a) consistency of the child's statements, (b) use of developmentally appropriate language, (c) presence of idiosyncratic details, (d) spontaneity of comments, (e) plausibility of incident(s), (f) emotional reaction of the child, and (g) style of relating to the evaluator (e.g., candid style preferred; AACAP, 1997).

6. Psychological testing. The accusing parent and alleged perpetrator should be psychologically tested to assess personality functioning, along with any other adult (e.g., parent, live-together partner, grandparent) who plays a role in the allegation. The MMPI-2 and MCMI (II or III) are recommended because they provide information about Axis I (mental disorders) and Axis II (personality disorders) psychopathology. The alleged perpetrator should also be screened for substance abuse problems, which are common among offenders. This will involve detailed questioning about present and past drug/alcohol usage, use of screening inventories such as the Substance Abuse Subtle Screening InventoryII, and analysis of drug/alcohol scales and critical items on the MMPI-2 and MCMI (II/III). If the alleged perpetrator has a past history of criminal convictions, the PCL-R ought to be given to assess psychopathy. It is essential to keep in mind that no single test or combination of tests will determine if the alleged perpetrator sexually offended.

Psychological testing of the alleged victim will depend on the age of the child and the level of functioning. Children with apparent or suspected disabilities (e.g., mental retardation, learning disability, language impairment, and emotional impairment) 
should be thoroughly tested (e.g., intellectual, academic, and personality areas) because it may assist in preparing for the interview with the alleged victim (i.e., understanding receptive and expressive language skills, memory ability, and level of general functioning). If no obvious impairment is evident, a cursory assessment can occur, using only self-report objective inventories to screen for depression, anxiety, and posttraumatic stress disorder. However, administration of these inventories is dependent on age and reading level. Projective techniques should be avoided in a forensic evaluation (Lilienfeld et al., 2000). Parents and teachers should complete social-emotional rating scales on the child, such as the Child Behavior Checklist (CBCL). The CBCL is recommended because it is psychometrically sound, allows direct comparison of parent, teacher, and self-report responses, and has a Sex Problem subscale that subtly assesses inappropriate sexual behavior. The CSBI (Child Sexual Behavior Inventory) is a useful, but transparent, instrument. Caution should be used in interpreting the results if completed by the accusing mother. In such cases, it may be preferable to have another caregiver (e.g., babysitter, child-care provider) complete the form. Regardless, it is important to note that the CSBI should not be used in isolation as a primary indicator of sexual abuse (Friedrich, 1993).

7. Assessment of the alleged perpetrator's sexual history. A critical part of this process involves collecting a detailed psychosexual history, in addition to the psychosocial history mentioned above. The Revised Psychosexual Life History Inventory (Nichols $\&$ Molinder, 1999) is recommended for this purpose. This 19-page questionnaire covers all major areas, including the factors outlined in Table 5. After the alleged perpetrator has completed the questionnaire, it should be used as an interview guide to gather additional information and to clarify issues. Documentation and collateral sources play a major role in identifying inconsistencies and areas that need to be confronted. This is particularly important in these types of evaluations because offenders tend to minimize, deny, and distort their behavior. Also, it is important for the evaluator to explore with the alleged perpetrator different types of paraphilia, such as bestiality, exhibitionism, fetishism, frottage, sadism, and pedophilia, both in terms of fantasies and actual behavior (Becker \& Quinsey, 1993). Furthermore, it is critical to assess a history of sexual boundary testing with the alleged victim and others.

Two other specialized instruments that show promise for assessing sexual behavior are the Multiphasic Sex Inventory-II and the Clarke Sex History Questionnaire for Males-Revised; however, these measures lack adequate research at this time to support their use in a forensic setting. As mentioned earlier, it is not recommended that the Abel Assessment, polygraph, or the penile plethysmograph be used in these types of evaluations.

8. Parent-child observations. The observation session is a common procedure in typical child custody evaluations (Bow \& Quinnell, 2001), but it becomes controversial when one of the parent figures has allegedly sexually abused a child. It is important to reiterate that an observation alone will not indicate if a child has been abused or not; however, it may provide information about the interaction pattern, attachment, parenting style, and comfort level of the child around the alleged perpetrator. If the child is going to be observed with the alleged perpetrator, it should occur in accordance with standard observation protocols, but under the continuous supervision of the evaluator. It also should occur at the end of the evaluation, following the forensic interviews with both the alleged victim and alleged perpetrator, and after it has been determined that the procedure is unlikely to have a negative impact on the child. An observation should also occur with the other parent(s) to provide a baseline for comparison.

9. Collateral contacts. Many collateral contacts are necessary and occur throughout the evaluation process. Of course, releases of information are usually needed and should be obtained at the beginning of the evaluation. Even though reports may be available from the police, Protective Services, or doctor's office, it is best to make personal contact with these people. Many times information will be conveyed orally that is not in writing. Contacts with the school, friends, former spouses or live-together partners, and relatives may be necessary too. All collateral contacts must be notified up front about the purpose of the forensic evaluation and the limits of confidentiality. Overall, collateral contacts play a major role in understanding the family dynamics and veracity of the allegation.

10. Formulating the findings. The final stage involves the analyses of data collected and the integration of all information into a comprehensive, written report. The focus should be on the referral question. The specific procedures used and areas assessed should be outlined, along with the hypotheses tested. Trends in the data ought to be highlighted, along with limitations and inconsistencies. Findings should be presented in a logical and meaningful way, clearly showing how conclusions were drawn. Detailed recommendations also need to be outlined, based on the findings of the evaluation.

It is hoped that by using the proposed forensic model outlined above, psychologists will provide sound, legally defensible evaluations that will protect the welfare of all parties and serve the best interests of children. It is further hoped that the findings from this study will stimulate discussion and research and spur action on the part of APA to develop formal, comprehensive guidelines for professional practice in these complex cases. On the basis of earlier findings (Bow \& Quinnell, 2001), it is clear that psychologists and their clients benefit from such guidance.

\section{References}

American Academy of Child and Adolescent Psychiatry. (1997). Practice parameters for the forensic evaluation of children and adolescents who may have been physically or sexually abused. Journal of the American Academy of Child and Adolescent Psychiatry, 36, 423-442.

American Professional Society on the Abuse of Children. (1990). Guidelines for psychosocial evaluation of suspected sexual abuse in young children. Chicago: Author.

American Psychological Association. (1994). Guidelines for child custody evaluations in divorce proceedings. American Psychologist, 49, 677680 .

American Psychological Association, Committee on Professional Practice and Standards, A Committee of the Board of Professional Affairs. (1995). Twenty-four questions (and answers) about professional practice in the area of child abuse. Professional Psychology: Research and Practice, 26, 377-385.

Association for the Treatment of Sexual Abusers. (2001). Practice standards and guidelines for members of the Association for the Treatment of Sexual Abusers. Beaverton, OR: Author.

Becker, J. V., \& Murphy, W. D. (1998). What we know and do not know about assessing and treating sexual offenders. Psychology, Public Policy, and Law, 4, 116-137. 
Becker, J. V., \& Quinsey, V. L. (1993). Assessing suspected child molesters. Child Abuse \& Neglect, 17, 169-174.

Benedek, E., \& Schetky, D. (1985). Allegations of sexual abuse in child custody and visitation disputes. In E. Benedek \& D. Schetky (Eds.), Emerging issues in child psychiatry and the law (pp. 145-156). New York: Brunner/Mazel.

Bow, J. N., \& Quinnell, F. A. (2001). Psychologists' current practices and procedures in child custody evaluations: Five years after American Psychological Association Guidelines. Professional Psychology: Research and Practice, 32, 261-268.

Ceci, S. J., \& Bruck, M. (1995). Jeopardy in the courtroom: A scientific analysis of children's testimony. Washington, DC: American Psychological Association.

Committee on Ethical Guidelines for Forensic Psychologists. (1991). Specialty guidelines for forensic psychologists. Law and Human Behavior, 15, 655-665.

Conte, J. R., Sorenson, E., Forgarty, L., \& Peela Rosa, J. (1991). Evaluating children's reports of sexual abuse: Results from a survey of professionals. American Journal of Orthopsychiatry, 61, 428-437.

Dammeyer, M. D. (1998). The assessment of child sexual abuse allegations: Using research to guide clinical decision making. Behavioral Sciences and the Law, 16, 21-34.

Ehrenberg, M. F., \& Elterman, M. F. (1995). Evaluating allegations of sexual abuse in the context of divorce, child custody, and access disputes. In T. Ney (Ed.), True and false allegations of child sexual abuse (pp. 209-230). New York: Brunner/Mazel.

Ellis, E. M. (2000). Divorce wars: Intervention with families in conflict. Washington, DC: American Psychological Association.

Friedrich, W. N. (1993). Sexual behavior in sexually abused children. Violence Update, 3, 8-11.

Gardner, R. (1987). The parental alienation syndrome and the differentiation between fabricated and genuine sex abuse. Cresskill, NJ: Creative Therapeutics.

Gardner, R. (1992). True and false accusations of child sexual abuse. Cresskill, NJ: Creative Therapeutics.

Haralambie, A. M. (1999). Child sexual abuse in civil cases: A guide to custody and tort action. Chicago: American Bar Association.

Hare, R. (1998). Psychopaths and their nature: Implications for the mental health and criminal justice system. In T. Millon, E. Simonsen, M. Birket-Smith, \& R. Davis (Eds.), Psychopathy: Antisocial, criminal, and violent behavior (pp. 188-223). New York: Guilford Press.

Kendall-Tackett, K. A., Williams, L. M., \& Finkelhor, D. (1993). Impact of sexual abuse on children: A review and synthesis of recent empirical studies. Psychological Bulletin, 113, 164-180.

Kuehnle, K. (1996). Assessing allegations of child sexual abuse. Sarasota, FL: Professional Resource.

Kuehnle, K. (1998). Child sexual abuse evaluations: The scientistpractitioner model. Behavioral Sciences and the Law, 16, 5-20.

Lamb, M. E., Orbach, Y., Sternberg, K. J., Hershkowitz, I., \& Horowitz, D. (2000). Accuracy of investigators' verbatim notes of their forensic interviews with alleged child abuse victims. Law and Human Behavior, 24, 699-708.

Lanyon, R. I. (2001). Psychological assessment procedures in sex offending. Professional Psychology: Research and Practice, 32, 253-260.

Lilienfeld, S. O., Wood, J. J., \& Garb, H. N. (2000). The scientific status of projective techniques. Psychological Science in the Public Interest, 1 , $27-66$.
McGleughlin, J., Meyer, S., \& Baker, J. (1999). Assessing sexual abuse allegations in divorce, custody, and visitation disputes. In R. M. Galatzer-Levy \& L. Kraus (Eds.), The scientific basis of child custody decisions (pp. 357-388). New York: Wiley.

McGraw, J. M., \& Smith, H. A. (1992). Child sexual abuse allegations amidst divorce and custody proceedings: Refining the validation process. Journal of Child Sexual Abuse, 1, 49-62.

Myers, J. E. B. (1992). Legal issues in child abuse and neglect. Thousand Oaks, CA: Sage.

Myers, J. E. B. (1997). A mother's nightmare-incest: A practical legal guide for parents and professionals. Thousand Oaks, CA: Sage.

Nichols, H. R., \& Molinder, I. (1984). The Multiphasic Sex Inventory. Tacoma, WA: Nichols and Molinder Assessments.

Nichols, H. R., \& Molinder, I. (1996). Multiphasic Sex Inventory II. Tacoma, WA: Nichols and Molinder Assessments.

Nichols, H. R., \& Molinder, I. (1999). Psychosexual Life History Inventory. Tacoma, WA: Nichols and Molinder Assessments.

Palmer-Percy, M. (1992). State v. Floody: The admissibility of expert testimony regarding "child sexual abuse syndrome." South Dakota Law Review, 38, 189-201.

Poole, D. A., \& Lamb, M. E. (1998). Investigative interviews of children: A guide for helping professionals. Washington, DC: American Psychological Association.

Quinnell, F. A., \& Bow, J. N. (2001). Psychological tests used in child custody evaluations. Behavioral Sciences and the Law, 19, 491-501.

Quinsey, V. L., \& Lalumiere, M. (2001). Assessment of sexual offenders against children (2nd ed.). Thousand Oaks, CA: Sage.

Salter, A. C. (1988). Treating child sex offenders and victim: A practical guide. London: Sage.

Stahl, P. M. (1999). Complex issues in child custody evaluations. Thousand Oaks, CA: Sage.

Summit, R. (1983). The child sexual abuse accommodation syndrome. Child Abuse and Neglect, 7, 177-193.

Thoennes, N., \& Tjaden, P. G. (1990). The extent, nature, and validity of sexual abuse allegations in custody/visitation disputes. Child Abuse and Neglect, 14, 151-163.

Underwager, R., \& Wakefield, H. (1995). Special problems with sexual abuse cases. In J. Ziskin (Ed.), Coping with psychiatric and psychological testimony (pp. 1315-1370). Los Angeles, CA: Law and Psychology Press.

Wakefield, H., \& Underwager, R. (1991). Sexual abuse allegations in divorce and custody disputes. Behavioral Sciences and the Law, 9, 451-468.

Walker, N. E., \& Hunt, J. S. (1998). Interviewing child victim-witnesses: How you ask is what you get. In C. P. Thompson, D. J. Herrmann, J. D. Read, D. Bruce, D. G. Payne, \& M. P. Toglia (Eds.), Eyewitness memory: Theoretical and applied perspectives (pp. 55-87). Mahwah, NJ: Erlbaum.

Zorza, J. (1999). Why courts are reluctant to believe and respond to allegations of incest. In Barbara K. Schwartz (Ed.), The sex offender: Theoretical advances, treating special populations and legal developments (Vol. 3, chap. 33, pp. 1-14). Kingston, NJ: Civic Research Institute.

Received November 19, 2001

Revision received July 11, 2002 Accepted July 16, 2002 